\title{
The Light Metals Division: Five Committees, One Mission
}

\author{
Wolfgang Schneider
}

The Light Metals Division (LMD) is one of five technical divisions of TMS.

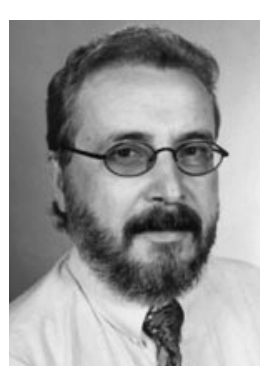

Its mission is to serve professionals in the traditional and emerging light metals fields, and to fulfill this mission, the LMD relies on five committees representing specific technologies within the light-metals community.

The long-established Aluminum Committee addresses technologies related to the primary aluminum industry and organizes the well-known Light Metals Program including Reduction Technology, Electrodes, Alumina and Bauxite, and Cast Shop Technology, at the TMS Annual Meeting. The Light Metals conference proceedings has developed into highly valued reference literature in the aforementioned areas.

The Aluminum Processing Committee, founded in 2008, provides a forum for the downstream industry, mainly rolling, shape casting, and alloy development. The committee's symposia organized at the annual meeting are currently published in separate proceedings, but in the future a common proceedings volume is planned, similar to the Light Metals book.

The Magnesium Committee provides a forum for the exchange of science and technology issues associated with magnesium production and use. The magnesium program during the annual meeting has increased significantly in recent years, with papers published in the highly recognized Magnesium Technology.

The Recycling and Environmental Technology Committee is a joint committee with the Extraction \& Process- ing Division (EPD). Its objective is to promote the interaction of the different technical functions to broaden and disseminate knowledge within the metals and materials industry regarding recycling, environmental impact of processes, and the treatment of process waste.

Also new to the LMD is the Energy Committee, founded in 2008 as a joint committee with the EPD. It is the mission of this committee to promote the sustainable production and manufacture of minerals, metals, and materials by fostering technical solutions to increase process efficiency, decrease energy consumption, minimize process emissions, and apply alternate sources of energy into material production processes. At the 2010 TMS Annual Meeting, the committee will offer four symposia covering alternative energy resources, greenhouse gas reduction, carbon management in manufacturing, and energy conservation in metals extraction.

The LMD is managed by the division council, which consists of the division officers, the technical committee chairpersons, and administrative committee representatives (programming, education, information technology, publications, membership and student development, and materials and society). The council meets once per year at the annual meeting and holds telephone conferences in between.

In addition to planning programming, the division rewards the professional accomplishments of its members. The most important awards are the Light Metals Distinguished Service Award and the Light Metals Technology Award, which are presented during the division luncheon at the annual meeting. The service award recognizes an individual with outstanding service to LMD; the technology award honors individuals who have demonstrated outstanding long-term service to the light metals industry; and the JOM best paper award honors the authors of a highquality contribution to JOM.

An important activity of LMD is to support students and to recruit young leaders. The division awards three scholarships annually for students and provides financial support for young professionals to attend the annual meeting and the Materials Science \& Technology fall conference. It is a clear strategic goal of LMD to interest young people in the division work and to educate them for future leadership.

Major efforts have been undertaken recently to strengthen the continuing education activities of LMD. As a result, specific courses or workshops will be offered with predetermined frequency, mainly at the annual meeting. This was started at the TMS 2009 Annual Meeting with courses on melt treatment, Bayer process, and direct chill casting of magnesium. Upcoming selected and proposed courses are:

- Aluminum Committee: Electrolysis Technology, Bayer Process, Melting and Melt Treatment, Casting and Modeling, Grain Refinement

- Aluminum Processing Committee: Material Science of Aluminum Alloys, Hot and Cold Rolling

- Magnesium Committee: Alloys, Casting, Corrosion, Deformation, Design with Magnesium

- Energy Committee: $\mathrm{CO}_{2}$ Reduction, Furnace Workshops

For further information please visit the LMD committee home pages.

Wolfgang Schneider is with Hydro Aluminium Deutschland GmbH and is the TMS Director of the Light Metals Division. 